\title{
REGULATION OF T LYMPHOCYTE SUBPOPULATIONS IN SPECIFIC PATHOGEN-FREE CHICKENS FOLLOWING EXPERIMENTAL FOWL ADENOVIRUS-VIII INFECTION
}

\author{
Chun-jie Wang* ${ }^{1}$, Siriguleng Yu ${ }^{1}$, Ao-ri-ge-le ${ }^{2}$, De-gang Jia ${ }^{1}$, Hong-qiang Yao ${ }^{1}$, Huai-ping Zhao ${ }^{1}$, H.S. Lillehoj ${ }^{3}$, Si-mu-ji- \\ de $^{2}$, Andrew CL Postnikoff ${ }^{4}$, Si-ri-gu-leng Xu ${ }^{1}$
}

${ }^{1}$ Department of Basic Veterinary, College of Veterinary Science, Inner Mongolia Agricultural University, Huhhot, Inner Mongolia, China, 010018; ${ }^{2}$ Department of Animal Production and Management, College of Animal Science, Inner Mongolia Agricultural University, Huhhot, Inner Mongolia, China, $010018 ;^{3}$ Animal Parasitic Diseases Laboratory, Animal and Natural Resources Institute, U. S. Department of Agriculture-ARS, Beltsville, MD. 20705, USA; ${ }^{4}$ College of Ecology and Environmental Science, Inner Mongolia Agricultural University, Huhhot, Inner Mongolia, China, 010018.

Submitted: April 02, 2011; Returned to authors for corrections: November 25, 2011; Approved: June $07,2012$.

\begin{abstract}
Two-day-old specific pathogen-free (SPF) chickens were divided into two groups. Group I was inoculated orally with fowl adenovirus VIII (FAV-VIII). Group II served as a negative control. Chickens were investigated at various days post-inoculation (dpi) by flow cytometric analysis for changes in $\mathrm{T}$ lymphocyte subpopulations in immune system and blood. In the thymus, $\mathrm{CD}^{+} \mathrm{T}$ lymphocytes were increased at $25 \mathrm{dpi}$, with significant increases in the FAV infected noted at $1,12,20 \mathrm{dpi}(\mathrm{p}<0.05)$. This was accompanied by a corresponding increase of $\mathrm{CD}^{+}$and $\mathrm{CD}^{+} \mathrm{T}$ lymphocytes. In the spleen, $\mathrm{CD}^{+}$and $\mathrm{CD} 4^{+} \mathrm{T}$ lymphocytes were increased significantly at $30 \mathrm{dpi}(\mathrm{p}<0.01)$ whereas $\mathrm{CD} 8^{+}$and TCR $\gamma \delta^{+} \mathrm{T}$ lymphocytes were decreased at $1(\mathrm{p}<0.05), 30 \mathrm{dpi}(\mathrm{p}<0.01)$. An increase of $\mathrm{CD}^{+}, \mathrm{CD}^{+}$and $\mathrm{CD} 8^{+} \mathrm{T}$ lymphocytes was noticed in peripheral blood, and accompanied by a decrease of TCR $\gamma \delta^{+} \mathrm{T}$ lymphocytes. These results demonstrated that infection with FAV-VIII causes significant fluctuations in T lymphocyte subpopulations in thymus, blood and spleen. It can be concluded that an infection with FAV-VIII has profound effects on the immune system, especially on cell mediated immune competency.
\end{abstract}

Key words: Cell mediated immune competency, Fowl adenovirus VII, Immune system, Peripheral blood, T lymphocyte subpopulations

\section{INTRODUCTION}

Inclusion body hepatitis (IBH) is caused by fowl adenovirus (FAV) and induces acute infection in chickens.
FAV is mainly infectious for young chickens, and is characterized by many pathological changes including necrotic hepatitis, acidophilus or basophilic inclusion body in the nucleus of liver cells. The main clinical symptoms of IBH 
include anemia and severe dysentery. IBH is most commonly seen in chickens between 3 and 7 week of age but has been reported as early as 7 days of age with high mortality (Howell et al. 1970). Normally IBH infection persists for 7 10 days. However, in some cases, persistence of IBH up to 20 days been reported (Reece et al. 1986). The outbreak of IBH has been reported in many countries, including an outbreak in Hohhot City of Inner Mongolia in 1991. The inclusion body hepatitis viruses are characterized as AAV VIII and AAV II, and designated as AAV-HB and AAV-HA respectively. There have been numerous studies on their pathology and pathogenesis (Wang et al. 1999). Gross lesion of IBH consists of hemorrhagic, pale yellow, swollen, friable livers. Typically, pancreas, leg, musculi thoracis, thymus and bursa are all hemorrhagic. Pathological changes of tissues, which are mainly expressed as necrosis of liver, eosinophilic and basophilic intranuclear inclusion bodies, have occurred in hepatocyte, Kupffer cell and pancreatic cells with karyomegaly. Histological sections from bursa, spleen and the thymus showed severe depletion, reticular cells and macrophage hyperplasia. In young chicks with IBH, the spleen and thymus were not fully developed (Hao et al. 1996; Pilkington et al. 1997). These chicks easily succumbed to other infectious diseases, such as infectious bursal disease virus (Sentíes-Cué CG et al. 2010). In the humoral immunity of IBH, broilerbreeder progenies from 30- to 50-wk-old grandparents vaccinated with AAV 8/11 vaccine were adequately protected against the AAV 8 and 11 serotypes and the Stanford strain (Alvarado IR et al. 2007). In order to analyze host immune response to FAV, we also investigated changes in $\mathrm{T}$ lymphocyte subpopulations in various lymphoid tissues following IBH infection.

\section{MATERIALS AND METHODS}

\section{Chicken}

Specified pathogen-free (SPF) eggs were obtained from the research centre of Beijing experimental animal, hatched in the Inner Mongolia Biological medicine plant, and raised at the Inner Mongolia Agricultural University. Chickens were separated into two groups: uninfected and FAV VIII-infected, and kept separately. They were raised by two people in two rooms, were supplied air disinfected with potassium permanganate three times, fed with hyperbaric steamed forage and boiled water. Ventilation was directly outside.

\section{Virus}

Fowl adenovirus VIII was obtained from China medicine checking institute, plaque purified and diluted in PH 7.4 0.01\% PBS. Infection of chickens with FAV VIII was carried out by oral inoculation of 2-day-old chickens with 105 plaque forming units (PFU) of FAV VIII.

\section{Experimental design and flow cytometry detection}

Ten chickens from both the uninfected and FAV-infected groups were separately sacrificed by taking blood from heart via injector till death at $1,3,5,7,9,12,15,20,25$ and 30 days post inoculation. Lymphocytes were purified by density gradient separation using $1 \mathrm{ml}$ heparin anticoagulative blood and $1 \mathrm{ml} \mathrm{PH} \mathrm{7.4,} 0.001 \%$ PBS mixture added gently on the $1 \mathrm{ml}$ density gradient separation (the main components were glucosan and diatrizoate meglumine) (1.077, HongRi Biotec.). Lymphocytes from thymus and spleen were prepared by filtrating through 200-mesh cell screen after softly mincing on it (Yin \& Liu 1999). For each antibody, $1 \times 10^{6} / \mathrm{ml}$ live lymphocytes were incubated with CD3-FITC/CD4-R-PE, CD3FITC/CD8-R-PE or CD3-FITC/TCR $\gamma \delta$-R-PE antibodies (Serotec.) at $4^{\circ} \mathrm{C}$ for 30 minuets, washed with PBS (PH7.4, $\left.0.01 \mathrm{M}, 4^{\circ} \mathrm{C}\right) 3$ times by centrifuging at $2000 \mathrm{rpm}$ for $5 \mathrm{~min}$ each time at $4^{\circ} \mathrm{C}$. Staining was assessed by flow cytometry on 10,000 live cells, data from flow cytometry was analyzed using with the Cell Quest software (BD Biotec.).

\section{Statistics}

Data from the two samples was analyzed using parametric 
t tests (Kiyoshi 2001).

\section{RESULTS}

\section{Gross lesions}

Infected chickens showed hemorrhagic, pale yellow, swollen, friable livers with white foci of necrosis. Hemorrhagic tissues were present in pancreas, leg and musculi thoracis etc yet. Hemorrhagic tissue was also seen in the thymus and bursa. Three chickens died separately at $5 \mathrm{dpi}$, and two more died at $6 \mathrm{dpi}$, providing a mortality rate of $0.05 \%$. The other infected chickens' body weights were also lower than control.

\section{Regulations of $\mathrm{T}$ lymphocytes and its subpopulations}

In thymus: Thymus $\mathrm{CD}^{+} \mathrm{T}$ lymphocyte was increased significantly at $1,12,20 \mathrm{dpi}(\mathrm{p}<0.05)$, was not increased significantly at $7,9,25 \mathrm{dpi}(\mathrm{p}>0.05)$, and was decreased significantly at $3,15 \mathrm{dpi}(\mathrm{p}<0.05)$ (Fig.1).

$\mathrm{CD}^{+} \mathrm{CD}^{+} \mathrm{T}$ lymphocyte increased significantly at $12 \mathrm{dpi}$ $(\mathrm{p}<0.05)$, and decreased extremely significantly at 30dpi $(\mathrm{p}<0.01)$ (Fig.2).

$\mathrm{CD}^{+} \mathrm{CD}^{+} \mathrm{T}$ lymphocyte increased in 1-3, 12-30 dpi, with significant increase at $20,30 \mathrm{dpi}(\mathrm{p}<0.05)$. However, there was significant decrease at 5-9dpi(p>0.05) (Fig.3).

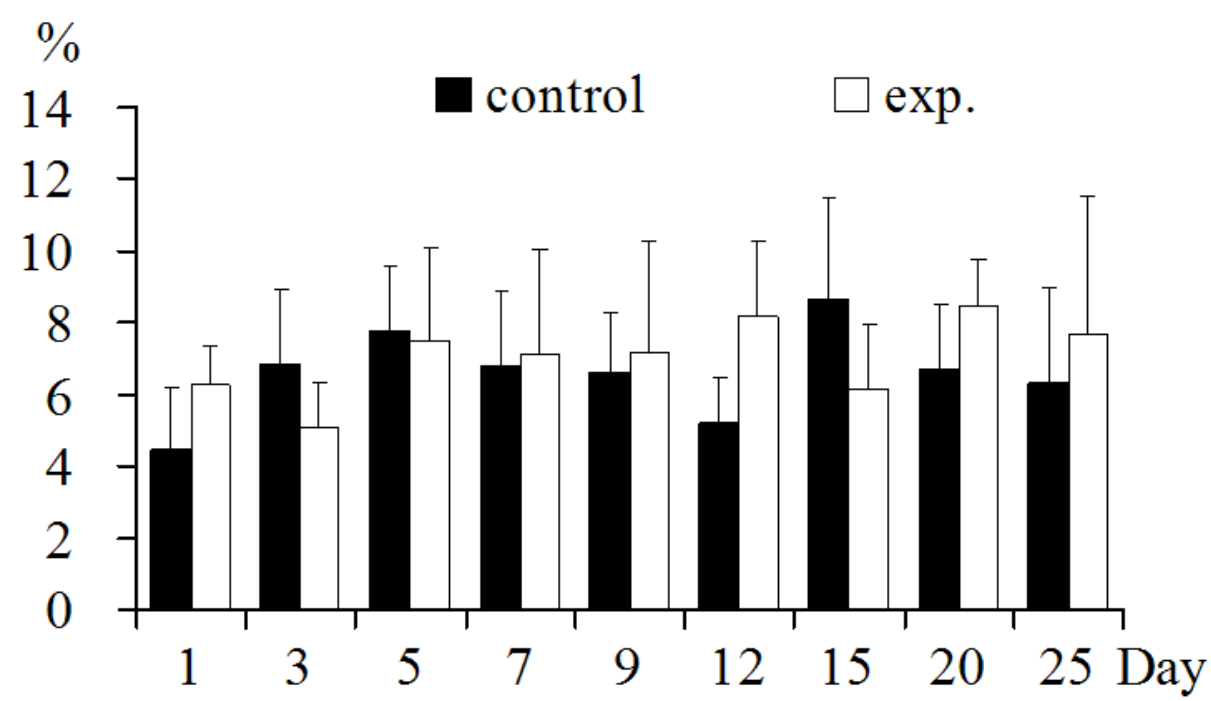

Figure 1. $\mathrm{CD} 3^{+} \mathrm{T}$ lymphocytes in thymus: $\mathrm{CD} 3^{+} \mathrm{T}$ lymphocyte increased significantly in 1,12, 20 days post inoculation $(\mathrm{p}<0.05)$ or not significantly in 7, 9, 25 days, decreased significantly in 3,15 days post inoculation $(\mathrm{p}<0.05)$.

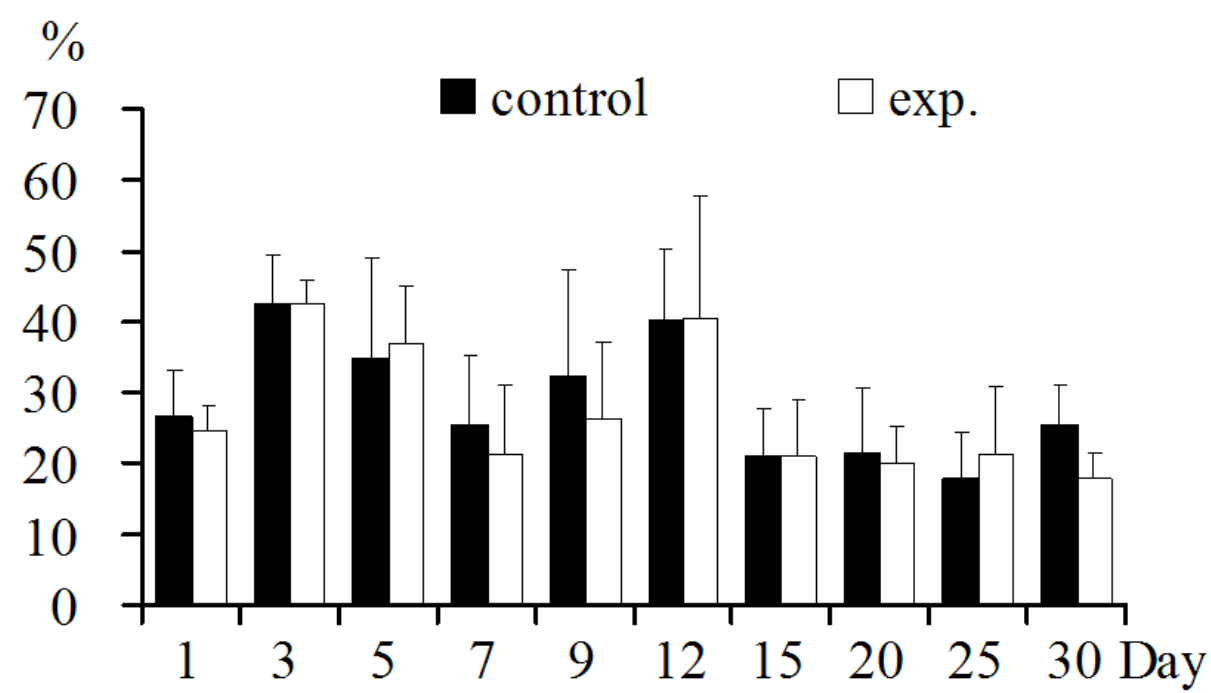

Figure 2. $\mathrm{CD}^{+} \mathrm{T}$ lymphocytes in thymus: $\mathrm{CD} 4^{+} \mathrm{T}$ lymphocyte increased significantly in 12 day $(\mathrm{p}<0.05)$ and decreased extremely significantly in 30 day $(\mathrm{p}<0.01)$ post inoculation. 


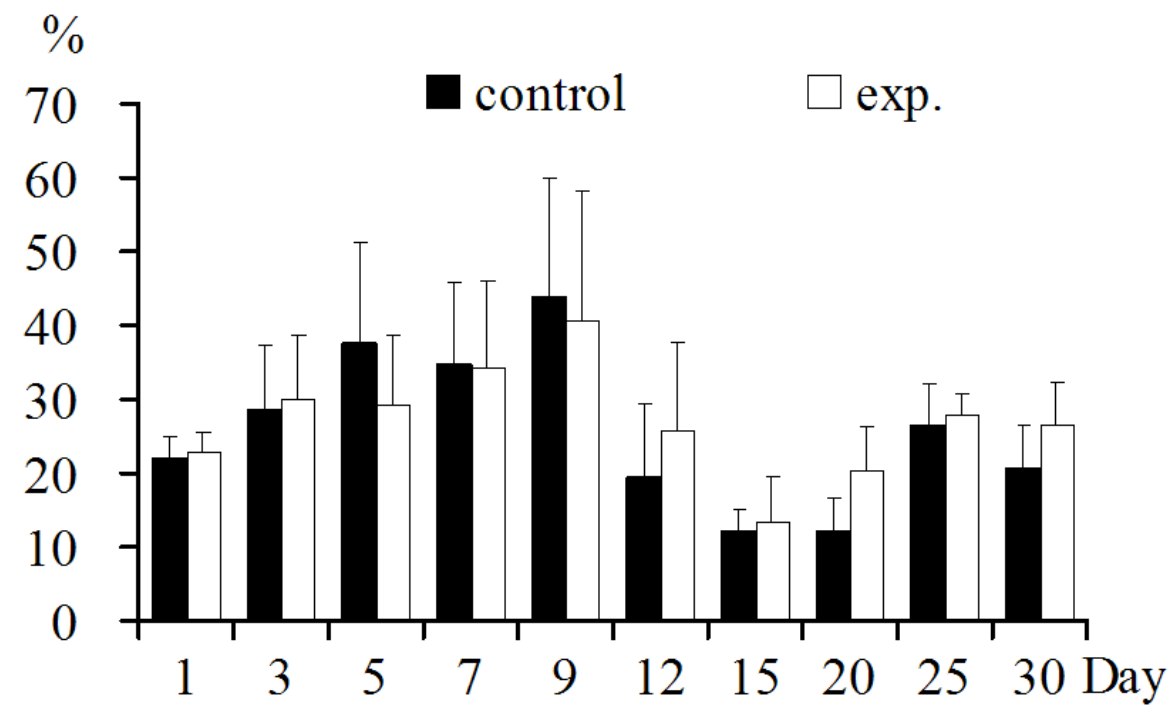

Figure 3. $\mathrm{CD}^{+} \mathrm{T}$ lymphocytes in thymus: $\mathrm{CD} 8^{+} \mathrm{T}$ lymphocyte increased 1-3, 12-30 dpi and significantly in $20,30 \mathrm{dpi}(\mathrm{p}<0.05)$. Decreased in 5-9 dpi.

In spleen: Spleen TCR $\gamma \delta^{+} \mathrm{T}$ lymphocyte increased only on 5, 7, 15, 20 dpi ( $\mathrm{p}>0.05)$. It decreased on all other days post inoculation ( $\mathrm{p}>0.05$ ) (Fig.4).

$\mathrm{CD}^{+} \mathrm{T}$ lymphocyte increased in 1-3, 9-30dpi ( $\left.\mathrm{p}>0.05\right)$ and extremely significantly in $30 \mathrm{dpi}(\mathrm{p}<0.01)$. Non significant decrease was noted on 5, 7 dpi (Fig.5).
$\mathrm{CD}^{+} \mathrm{CD}^{+} \mathrm{T}$ lymphocytes all increased and were extremely significantly at $30 \mathrm{dpi}(\mathrm{p}<0.01)$. There was only non significant decrease in 1, 5, 7 dpi (Fig.6).

$\mathrm{CD}^{+} \mathrm{CD}^{+} \mathrm{T}$ lymphocyte increased in 9-15 dpi $(\mathrm{p}<0.05)$, with non significant decrease in 1-7, 20-30 dpi (Fig.7).

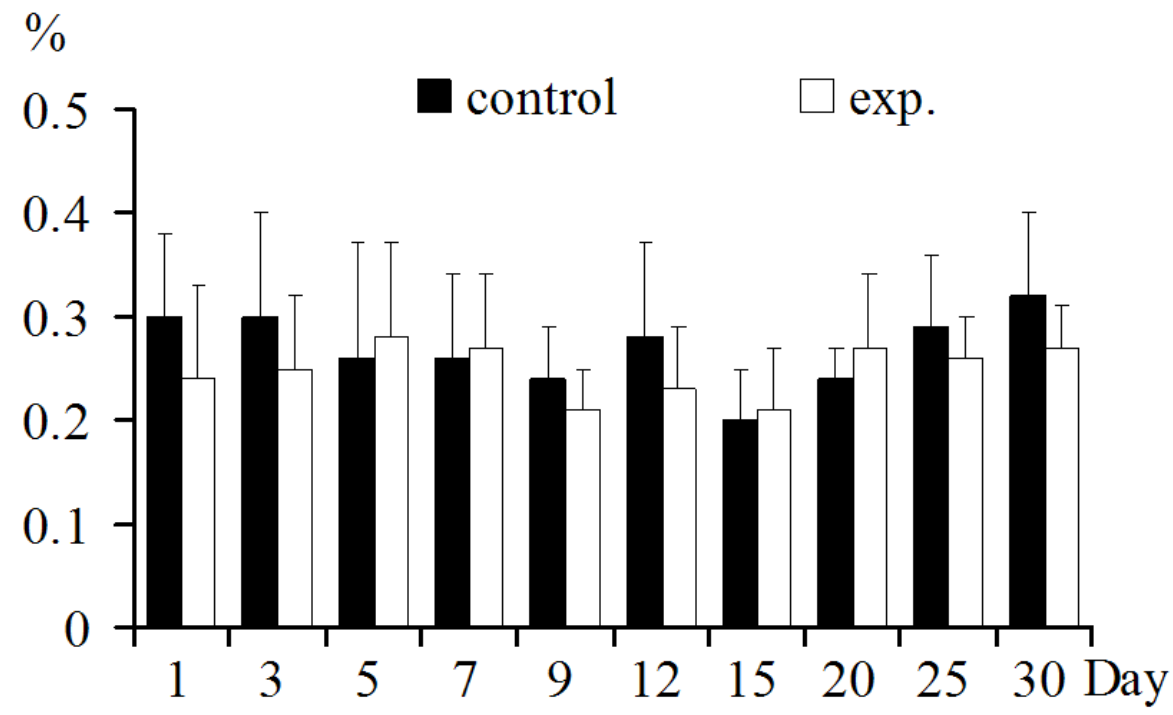

Figure 4. TCR $\gamma \delta^{+} \mathrm{T}$ lymphocytes in spleen: TCR $\gamma \delta^{+} \mathrm{T}$ lymphocyte increased only in 5, 7, 15, 20 dpi. Decreased in other days post inoculation. 


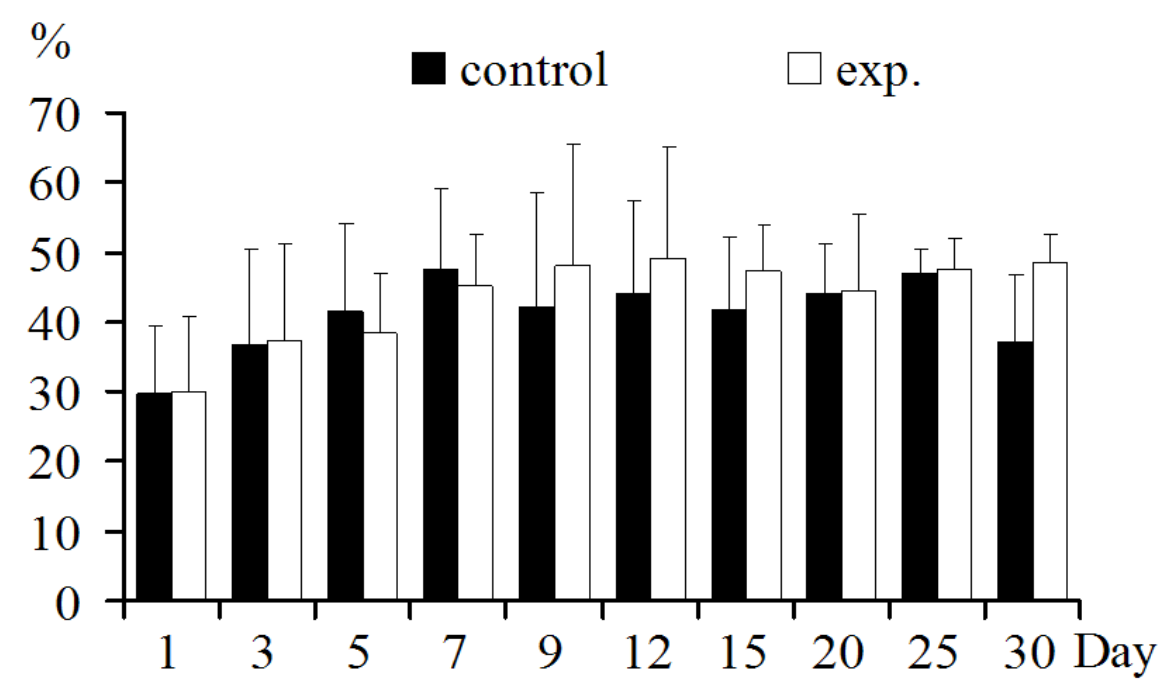

Figure 5. $\mathrm{CD}^{+} \mathrm{T}$ lymphocytes in spleen: $\mathrm{CD}^{+} \mathrm{T}$ lymphocyte increased 1-3, 9-30dpi and extremely significantly in 30-day post inoculation $(\mathrm{p}<0.01)$.

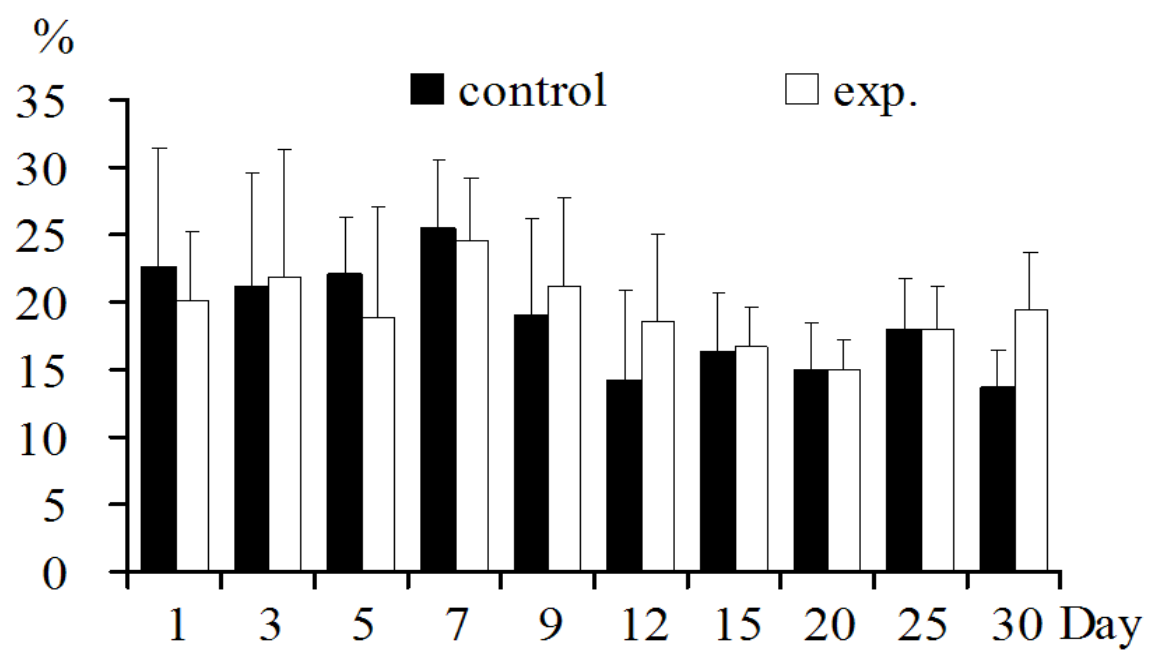

Figure 6. $\mathrm{CD}^{+} \mathrm{T}$ lymphocytes in spleen: $\mathrm{CD} 4^{+} \mathrm{T}$ lymphocyte increased except1, 5-7 dpi and extremely significantly in $30 \mathrm{dpi}(\mathrm{p}<0.01)$.

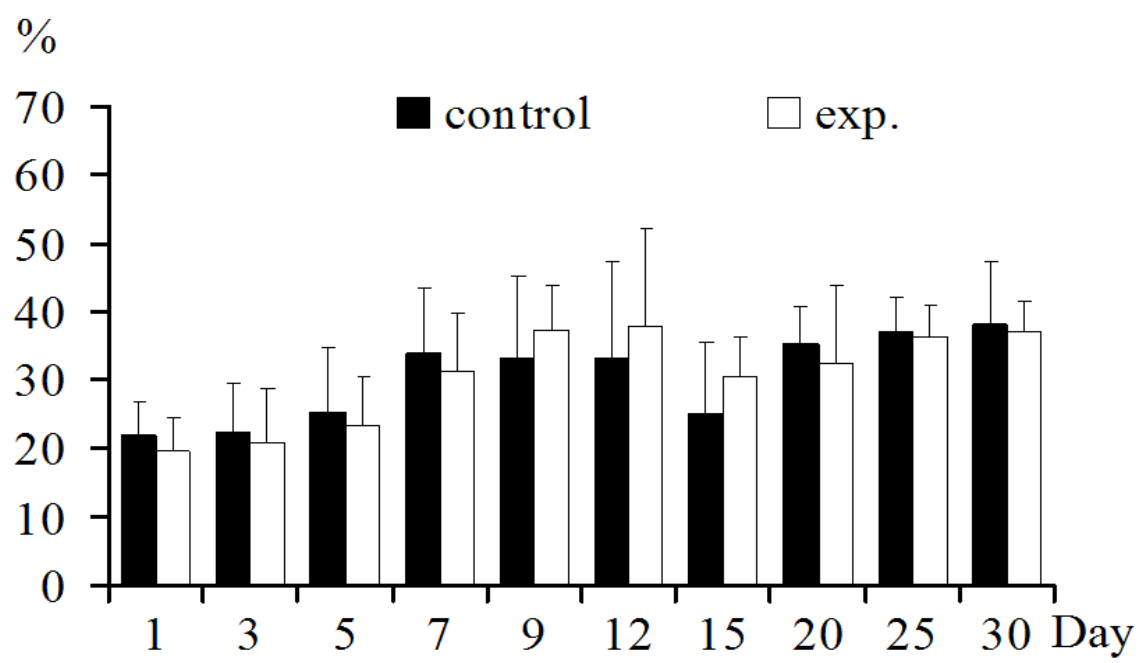

Figure 7. $\mathrm{CD} 8^{+} \mathrm{T}$ lymphocytes in spleen: $\mathrm{CD} 8^{+} \mathrm{T}$ lymphocyte increased significantly in 9-15 days post inoculation. Decreased in 1-7, 20-30 days post inoculation. 
In blood: Blood/TCR $\gamma \delta^{+} \mathrm{T}$ lymphocyte: TCR $\gamma \delta^{+} \mathrm{T}$ lymphocyte decreased, except in 3,5 dpi. The decrease was significant in 7 dpi $(\mathrm{p}<0.05)$ (Fig.8).

$\mathrm{CD}^{+} \mathrm{T}$ lymphocyte increased significantly in $12 \mathrm{dpi}$ $(p<0.01)$. It decreased significantly in $1(p<0.01), 30(p<0.05)$ dpi (Fig.9).
$\mathrm{CD}^{+} \mathrm{CD}^{+} \mathrm{T}$ lymphocyte increased significantly in $25 \mathrm{dpi}$ $(p<0.05)$. It decreased significantly in 1,30 dpi $(p<0.05)$ (Fig.10).

$\mathrm{CD}^{+} \mathrm{CD} 8^{+} \mathrm{T}$ lymphocyte increased significantly in 9 $(p<0.05), 25(p<0.01)$ dpi. It decreased significantly in $1-3,30$ dpi (p<0.05) (Fig.11).

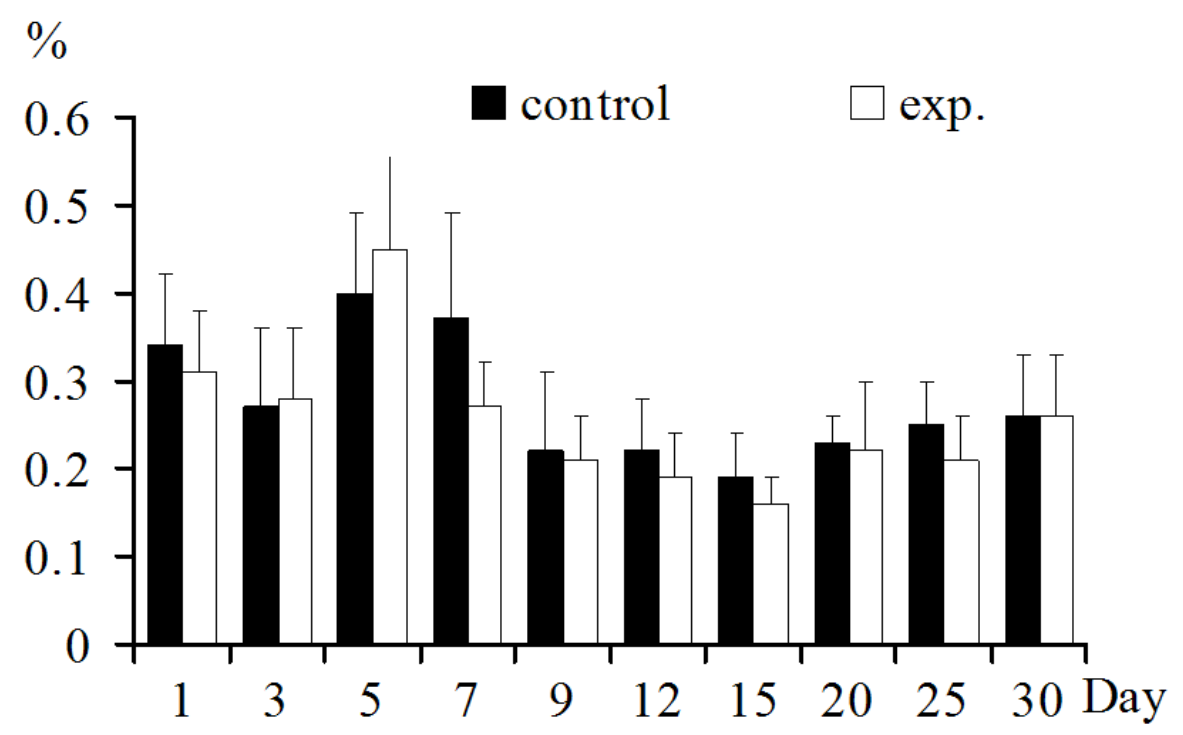

Figure 8. TCR $\gamma \delta^{+}$T lymphocytes in blood: TCR $\gamma \delta^{+} \mathrm{T}$ lymphocyte increased in 3-5 days, and decreased in other days and significantly in 7-day $(\mathrm{p}<0.05)$ post inoculation.

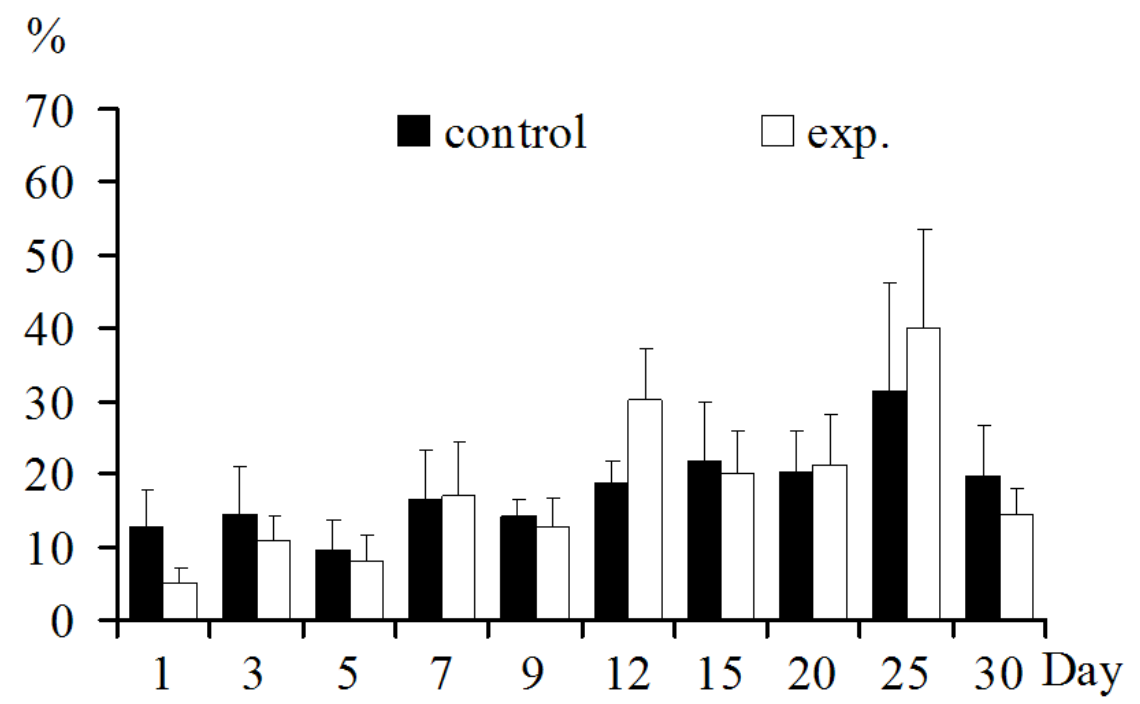

Figure 9. $\mathrm{CD}^{+} \mathrm{T}$ lymphocytes in blood: $\mathrm{CD} 3^{+} \mathrm{T}$ lymphocyte increased extremely significantly in 12-day $(\mathrm{p}<0.01)$ post inoculation. Decreased significantly in $1(\mathrm{p}<0.01), 30(\mathrm{p}<0.05)$ days post inoculation. 


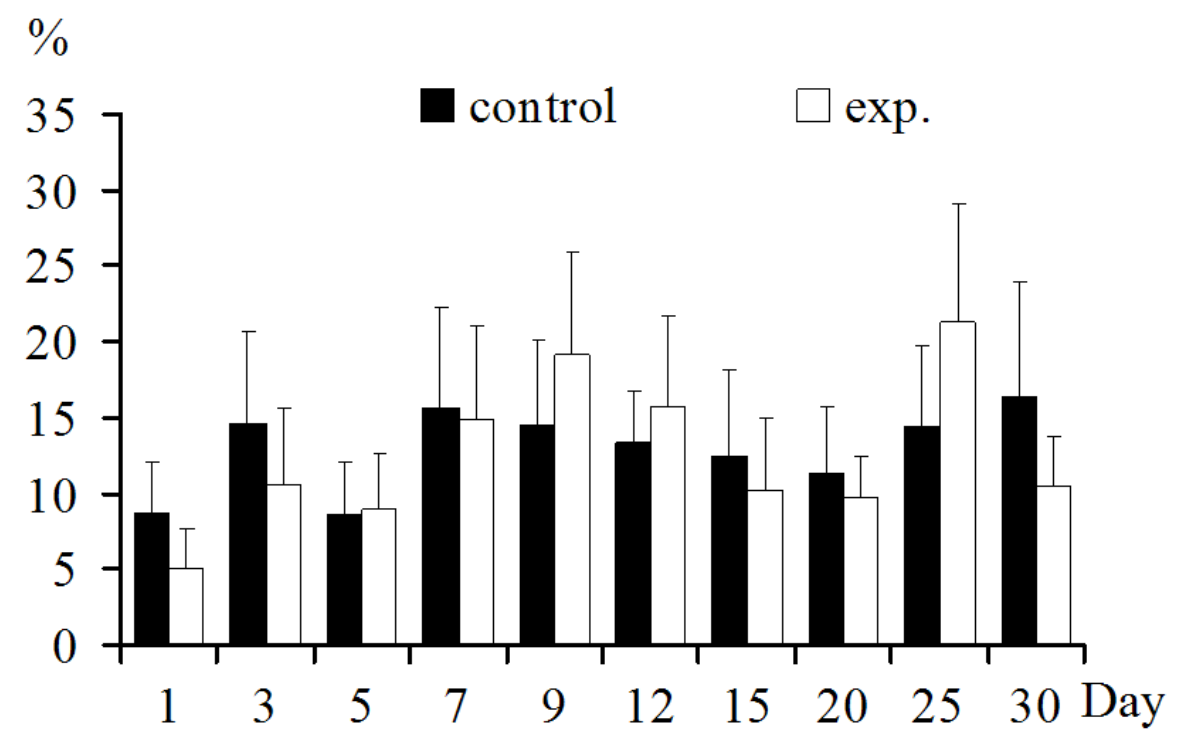

Figure 10. $\mathrm{CD}^{+} \mathrm{T}$ lymphocytes in blood: $\mathrm{CD} 4^{+} \mathrm{T}$ lymphocyte increased significantly in 25 -day post inoculation $(\mathrm{p}<0.05)$. Decreased significantly in 1,30 days post inoculation $(\mathrm{p}<0.05)$.

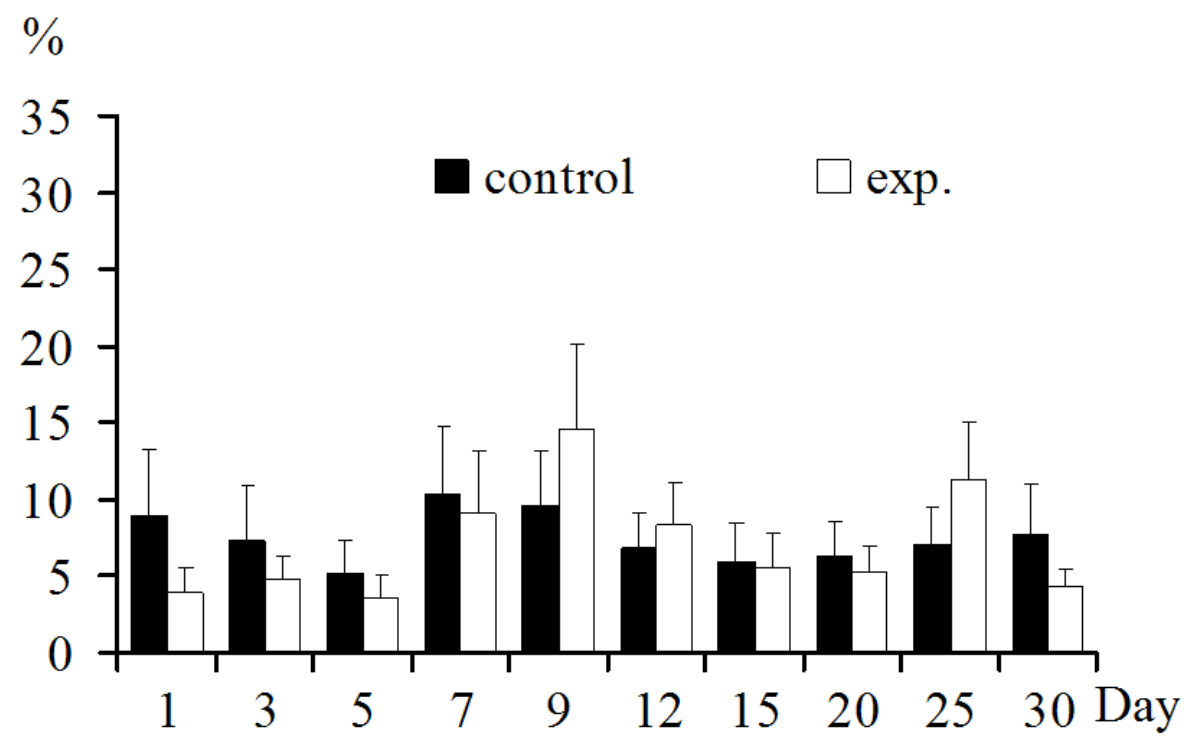

Figure 11. $\mathrm{CD} 8^{+} \mathrm{T}$ lymphocytes in blood: $\mathrm{CD} 8^{+} \mathrm{T}$ lymphocyte increased $9-15$ and significantly in $9(\mathrm{p}<0.05), 25(\mathrm{p}<0.01)$ days post inoculation. Decreased in 1-7, 20, 30 and significantly in $1-3(\mathrm{p}<0.05), 30(\mathrm{p}<0.01)$ days post inoculation.

\section{DISCUSSION}

Several workers have used ELISA and CIE to evaluate the humoral immune response of chicks infected with different clinical isolates (Maiti \& Sarkar 1997; Dawson \& Pronovost 1980; Calnek et al. 1982). The present study demonstrates for the first time that virulent fowl adenovirus $\gamma$ induces the response of $\mathrm{T}$ lymphocyte and its subpopulations in infected chicken in lymph organs and blood.

All gross lesions and pathological changes in the present study were the same as those reported before (Saifudin \& wilks 1991; Chandra et al.1999; Alemnesh W et al. 2011). Liver cell 
necrosis appeared severely in day 3-7 and day 12 of post inoculation (dpi) and also appeared slightly at 25 dpi in a few chickens. pathological change, including pathological changes of other organs, has 3 peaks during 1-30 dpi. The peaks were at 3-7 dpi, 12dpi and 25 dpi. These indicate that IBH will occur many times with only one exposure, but less severely every time. Body weight in the affected appeared less than the uninfected (Sentíes-Cué CG et al. 2010). This maybe due to lesions of liver cells influencing endocrine growth factors or other. Hemorrhagic and lymphocyte depletion also occurred in lymph organs. Lymphocytes proliferated in liver, pancreas and other organs both as dispersed and clumped groups. The immunology in the current IBH procedure interestingly differs from earlier studies made by Md. Saifuddin measuring neutralize antibody (Saifudin \& wilks 1991) which reported no T lymphocyte in IBH.

The thymus is essential for the maturation of $\mathrm{T}$ cells and the development of cell mediated immunity. $\mathrm{CD}^{+} \mathrm{T}$ lymphocyte increased significantly at 1, 12, $20 \mathrm{dpi}$. These days correspond to the start and the beginning stage of every pathological change. Significantly decrease occurred at 3, 15 dpi, which were after the virus invasions of 1, 12 dpi. These values indicate that mature $\mathrm{T}$ lymphocyte in the thymus activated and was significantly increased by the invasion of FAV $-\gamma$ at every beginning stage of pathological change. This was often followed by a significant decrease, which might be caused by the infection moving into spleen, blood or damaged by virus, because all necrosis and lymphocyte loss were seen in thymus at 3-15 dpi in the most sharply pathological changing.

$\mathrm{CD}^{+} \mathrm{CD}^{+} \mathrm{T}$ lymphocyte increased significantly at 20,30 dpi, and they all were in the preparing for serving into spleen and blood. $\mathrm{CD}^{+} \mathrm{T}$ lymphocyte was more active than $\mathrm{CD} 4^{+} \mathrm{T}$ cell in this case, because $\mathrm{CD}^{+} \mathrm{Tc}(\mathrm{TCL})$ can recognize the cell expressing antigen (virus) combined with MHC I and kill it; since the thymus was also infected with the virus here, and appeared hemorrhagic and depleted, so $\mathrm{CD}^{+} \mathrm{T}$ lymphocyte more activate and prolific in the infected than in the control (uninfected) population, except at 5-9 dpi which showed damage from the first attack by the virus.

The main immunological function of the spleen is to filter the blood by trapping blood borne micro-organisms and producing an immune response to them.

Spleen $\mathrm{CD}^{+} \mathrm{TCR} \quad \gamma \quad \delta^{+} \mathrm{T}$ lymphocyte showed no significant change, which means that $\mathrm{CD}^{+} \mathrm{TCR} \gamma \delta^{+} \mathrm{T}$ lymphocyte was neither degraded nor activated significantly by FAV- $\gamma$. Blood TCR $\gamma \delta^{+} \mathrm{T}$ lymphocyte levels generally decreased, with a significant decrease at $7 \mathrm{dpi}$, though there was an insignificant increase in 3-5dpi. This indicates that TCR $\gamma \quad \delta^{+} \mathrm{T}$ lymphocyte was slightly inhibited. TCR $\gamma \delta^{+} \mathrm{T}$ lymphocyte is present as $20 \%-25 \%$ of blood matured $\mathrm{T}$ cells in chicken (Yin \& Liu 1999). It may act as the first line of defense, TCR $\gamma \delta^{+} \mathrm{T}$ cell is express CTL granular as in NK cells including perforin, serine esterase1 and serine esterase2 (Nakata et al.1990). TCR $\gamma \delta^{+} \mathrm{T}$ cell also stimulates the secretion of many kinds of lymphokines (Spits et al.1990). It can introduce a cytotoxic action in killing tumor cell of NK cells. It was also significantly increased in little guts and spleen in coccid-infected chicken. However, it was inhibited in the IBH chickens in this study except in blood levels of the 3-5 dpi.

T lymphocytes and their subsets of spleen and blood cells all decreased significantly in the early time of virus inoculation. This was expressed through the pathologic damage of this disease and is consistent with the step of pathological changes of other organs; $\mathrm{CD}^{+}, \mathrm{CD}^{+}$and $\mathrm{CD}^{+} \mathrm{T}$ lymphocytes of spleen and blood all increased, often significantly, with a second pathological peak occurring at about $12 \mathrm{dpi}$. This may be the result of activating the memory $\mathrm{T}$ lymphocyte produced at the first peak, also coming from thymus. They were damaged during the anti-viral processes at 15-20dpi. There was a third pathological changing peak with corresponding increase at $25 \mathrm{dpi}$, followed by a significant decrease at 30dpi. These levels typically were only 2-3 days later than a significant increase in k1+ mono-macrophage in both spleen and blood, which can present antigens to lymphocytes and make lymphocyte proliferation. However, analysis of $\mathrm{k} 1+$ mono- 
macrophage response is beyond the scope of this paper, and is addressed by other studies. After the lymphocyte proliferation, there was once again subsequent damage.

If the virus had not been eliminated thoroughly in the end, they invaded hepatocytes and proliferated in them. Then the hepatocytes died and discharged the virus into blood, causing viremia (Saifudin \& Wilks 1991). This caused the activation of $\mathrm{M} \varphi$, which leads to cell immunological and humoral immunological to anti viral responses. After, $\mathrm{M} \varphi$ and lymphocytes were damaged and their count was lower than the control (in the same experiment no reported). The virus then invaded and proliferated in liver, pancreas, etc. cells again, causing the next viremia, and another immunologic response by activating the memory lymphocytes. This cycle continues to repeat. However, the pathological damage is lower every time, because the FAV- $\gamma$ invaded cells were correspondingly lower, and the so the immunological response was also lower. This was determined in another experiment detecting in situ pathogen.

These findings agree with the findings of some earlier reports, which state that adenovirus (HEV) infection depressed cell-mediated immune competency (Nagaraja et al. 1982; Suresh \& Sharma 1995; Singh et al. 2006). However, this conclusion is not universally accepted (Kumar et al. 1989; Lal et al. 1991).

\section{CONCLUSION}

These studies demonstrate that infection with FAV- $\gamma$ causes significant fluctuations in $\mathrm{T}$ lymphocyte subpopulations in the thymus, blood and spleen. It can be concluded that an infection with FAV- $\gamma$ has profound effects on the immune system, especially cell mediated immune competency. However, variation in the results of cellular immune competency means further studies with pathogenic strains of FAV are necessary.

\section{ACKNOWLEDGEMENTS}

This work was supported by the natural science fund of China (subject number: 30160067) and the Inner Mongolia natural science fund.

\section{REFERENCES}

1. Alemnesh, W.; Hair-Bejo, M.; Aini, I.; Omar, A.R. (2011). Pathogenicity of Fowl Adenovirus in Specific Pathogen Free Chicken Embryos. J Comp Pathol. Jun 24. [Epub ahead of print]

2. Alvarado, I.R.; Villegas, P.; El-Attrache, J. et al. (2007). Genetic characterization, pathogenicity, and protection studies with an avian adenovirus isolate associated with inclusion body hepatitis. Avian Dis. Mar; 51(1):27-32.

3. Calnek, B.W.; Shek, W.R. et al. (1982). Serological cross-reactivity of avian adenovirus serotypes in an enzyme-linked immunosorbent assay. Avian Dis. 26, 897-906.

4. Chandra, R.; Shukla, S.K. et al. (1999). The hydropericardium syndrome and inclusion body hepatitis in domestic fowl. Trop. Anim. Health. Pro. 32, 99-111.

5. Chun-jie, W.; Xian-pu, H.; Xi, L. (1998). Study on the Location of Virus Antigen pathogenesis of experimental inclusion body hepatitis in chicken. Master paper of Inner Mongolia agricultural University.

6. Dawson, G.J.; Pronovost, A.D. (1980). An enzyme-linked immunosorbent assay for detection of antibodies to avian adenovirus and avian adenovirus-associated virus in chickens. Avian Dis. 24,393-402.

7. Howell, J.; MacDonald, D.W.; Christian, R.G. (1970). Inclusion Body Hepatitis in Chicken. Can. Vet. J. 5, 99-101.

8. Ichihara, K. (2001). Statistics for Bioscience. 72-74. Nankodo publishers limited, Tokyo.

9. Kumar, U.K.; Krishnaswamy, S. et al. (1989). Cell mediated immune response to egg drop syndrome 76 (EDS-76) virus infection in chickens. Curr. Sci. 58,431-3.

10. Lal, B.; Maiti, N.K. et al. (1991). Cell mediated immune responses of chicks following fowl adenovirus type-1 infection. Comp. Immunol. Microbiol. Infect. Dis. 14, 55-8.

11. Maiti, N.K.; Sarkar, P. (1997). Humoral immune response of chicks to different clinical isolates of avain adenovirus type-1. Comp. Immun. Microbiol. infect. Dis. 1, 59-62.

12. Nagaraja, K.V.; Patel, D.A. et al. (1982). In vitro depression of the mitogenic response of lymphocytes from turkeys infected with HE virus. Am. J. Vet. Res. 43,134-6.

13. Nakata, M.; Smyth, M.J. et al. (1990). Constitutive expression of poreforming protein in peripheral blood gamma/delta T cells: implication for their cytotoxic role in vivo. J. Exp. Med.172, 1877-1880.

14. Pilkington, P.; Brown, T. et al. (1997). Adenovirus-induced inclusion body hepatitis in four-day-old broiler breeders. Avian Dis. 41, 472-474.

15. Reece, R.L.; Barr, D.C. et al. (1986). Observation on naturally occurring inclusion body hepatitis in Victorian chickens. Aust. Vet. J. 6, 201-202.

16. Saifudin, M.D.; Wilks, C.R. (1991). Pathogenesis of an acute viral 
hepatitis: inclusion body hepatitis in the chicken. Arch. Virol. 116, 3343.

17. Sentíes-Cué, C.G.; Wills, R.W.; Stayer, P.A. et al. (2010). Epidemiology and effect on production parameters of an outbreak of inclusion body hepatitis in broilers. Avian Dis. Mar; 54(1):74-8.

18. Singh, A.; Grewal, G.S. et al. (2006). Effect of fowl adenovirus-1 (IBH isolate) on humoral and cellular immune competency of broiler chicks. Comp. Immun. Microbiol. Infect. Dis. 29, 315-321.

19. Spits, H.; Yssel, H. et al. (1990). Analysis of antigen specificity of human TCR $\gamma \delta+$ T-cells. Res. Immunol. 141, 636-646.
20. Suresh, M.; Sharma, J.M. (1995). Haemorrhagic enteritis virus induced changes in the lymphocyte subpopulations in turkeys and the effect of experimental immunodeficiency on viral pathogenesis. Vet. Immonol. Immunopathol. 45, 139-50.

21. Xian-Pu, H.; Feng-Long, W.; Yu-Fang, G.U. (1996). A Study on pathology of inclusion body hepatitis in chicken. Inner Mongolia agricultural and husbandry institute journal. 47, 37-40.

22. Tian-Bang, Y.; Xing-You, L. (1999). Foul Immunology. 10-25. Chinese Agricultural Science and Technological press, Beijing. 